Research Article

\title{
Perception regarding AYUSH and integrative medicine among medical undergraduate students: a cross-sectional study
}

\author{
Roopali Somani*, Shrenik Vardhamane, Basavaraj Bidarimath, Md. Sajid
}

\begin{abstract}
Department of Pharmacology, Mahadevappa Rampure Medical College, Kalaburagi, Karnataka, India
\end{abstract}

Received: 05 April 2016 Accepted: 07 May 2016

\section{*Correspondence to: \\ Dr. Roopali Somani, \\ Email: somani_roopali \\ @yahoo.com}

Copyright: (C) the author(s), publisher and licensee Medip Academy. This is an openaccess article distributed under the terms of the Creative Commons Attribution NonCommercial License, which permits unrestricted noncommercial use, distribution, and reproduction in any medium, provided the original work is properly cited.

\begin{abstract}
Background: Promotion of AYUSH by government of India and the increasing utilization of AYUSH concurrently with allopathic medicine by patient population can lead to unfavourable outcomes. Sensitising medical students to AYUSH will equip them in better management of patients. The objective of this study was to determine the prevalence of AYUSH use among medical students and their perception regarding AYUSH and its possible integration in medical curriculum.

Methods: A Questionnaire based study was conducted on 450 medical undergraduate students of Mahadevappa Rampure Medical College, Kalaburagi, Karnataka, India from March 2015 to April 2015. Data obtained was analysed and presented as counts and percentages.

Results: Among the 380 respondents, it was found that 96 (25.2\%) students utilized AYUSH therapies; the most common indication for using them was for allergic disorders. Only $10 \%$ of the students believed that it caused less adverse effects. AYUSH utilization significantly increased in final year of medical studies. $71 \%$ of the students believed that AYUSH was useful; however they felt that scientifically unproven AYUSH therapies should be discouraged. 60\% of the students opined that integrated medicine is a better approach than using either system alone. Among 266 (70\%) students interested in learning AYUSH, $151(40 \%)$ students favoured AYUSH integration in medical curriculum as an elective subject.

Conclusions: Medical student's perception towards AYUSH and integrative medicine is positive. Students were in favour of learning AYUSH as an elective subject in medical curriculum.
\end{abstract}

Keywords: AYUSH, Integrative medicine, Perception, Questionnaire

\section{INTRODUCTION}

India is an amalgamation of different religions, cultures and beliefs. Patient's beliefs influence their choice of medicine. Indian patients have a wide variety of treatment modalities to choose, ranging from modern medicine to complementary and alternative (CAM) systems like ayurveda, homeopathy, unani, siddha, yoga and naturopathy (AYUSH).

About $70 \%$ of Indians reside in rural areas where there is an acute shortage of medical equipment's and modern medicine practitioners. $^{1,2}$ This resource constraint coupled with increased incidence of non-communicable illness, dissatisfaction with modern medicine and the promotion of ayurveda, yoga, naturopathy, unani, siddha and homeopathy (AYUSH) by the government of India has led to its burgeoning popularity. ${ }^{3}$

Indian government's ambitious plan to provide healthcare for all by adopting a pluralistic health policy which aims to integrate AYUSH and modern medicine has evoked mixed reactions. ${ }^{4}$ The feasibility of this plan depends on identifying the strengths of each system of medicine and development of integrated treatment options after rigorous evaluation. This can be achieved by training the future medical practitioners in the basics of all the systems of medicine so as to avoid potential drug 
interactions and give better guidance to patients regarding the best possible treatment option for the particular disease.

Studies conducted at Delhi, Mumbai and Bangalore reported that more than $50 \%$ of allopathic doctors routinely prescribed AYUSH medicines to patients but majority of them lacked knowledge on the basics of these modalities. $^{5-7}$

Integrative medicine is defined as an approach to the practice of medicine that makes use of the best-available evidence taking into account the whole person (body, mind, and spirit), including all aspects of lifestyle. It emphasizes the therapeutic relationship and makes use of both conventional and complementary/alternative approaches. ${ }^{8}$

Many countries including United States and China have implemented integrated medicine and offer undergraduate medical students courses in alternative medicine along with modern medicine. This training equips them to offer the right combination from all systems of medicine for the benefit of the patient. ${ }^{9}$

Recently a proposal for sensitizing medical undergraduates to AYUSH was put forth and amrutha university in Kerala has started courses on integrated medicine. ${ }^{10,11}$ Medical students attitude towards AYUSH and IM will determine the success of the government's plan and IM courses.

Hence this study was designed to assess the perception and prevalence of AYUSH use in undergraduate medical students and their opinion regarding integrative medicine courses.

\section{METHODS}

A cross sectional questionnaire based study was conducted on undergraduate medical students of Mahadevappa Rampure Medical College, Kalaburagi, Karnataka, India over a period of 2 months, from March 2015 to April 2015. Prior approval from institutional ethics committee was obtained. A semi-structured, selfadministered questionnaire was designed based on previous literature to assess the usage pattern and perception about AYUSH. The questionnaire was first pre-tested on 10 students and accordingly suitable modifications were made. The final version comprised of 22 close ended questions divided under four sectionsDemographic information usage pattern, perception about AYUSH and opinion on integrated medicine.

Apart from gender and year of study the demographic section did not include any question which revealed the identity of students. Under the usage pattern questions regarding the modality used, duration, indication, frequency, reason and satisfaction with AYUSH were asked. The perception section sought students opinion on effectiveness of AYUSH and their inclination to recommend these methods to patients in their future professional lives. The questions in perception and integrated medicine section were based on validated questionnaires- complementary health belief questionnaire (CHBQ) and integrated medicine attitude questionnaire (IMAQ) respectively. Questions were modified to include opinions only towards AYUSH and IM. $^{12,13}$

Students were explained in detail about the study objectives, procedure and their potential role in the study. They were also informed that participation was voluntary and their opinions were recorded anonymously. A total of 450 students, who agreed to participate in the study voluntarily and gave written informed consent were included. They were given 30 minutes to fill the form. A study co-ordinator was present nearby to address queries of the students. The data obtained was analysed using Microsoft Excel and Epi-Info version 7.

\section{RESULTS}

Out of 450 participants, 380 were analysed as there were 39 incomplete questionnaires and 31 non respondents. The response rate thus obtained was $84 \%$.

The mean age (standard deviation) of students was 20 $( \pm 1.25)$ years. The sample comprised of $229(60.26 \%)$ males and 151 (39.54\%) females. 221 (58.15\%) students were aware and could expand the term AYUSH.

\section{Usage pattern of AYUSH}

96(25.2\%) students reported using an AYUSH modality. AYUSH use was significantly more in final year students. Gender and other demographic variables had no significant effect on the pattern of AYUSH use n (Table 1). The most common indication for AYUSH use was for treating common cold, allergic rhinitis (34.3) (Figure 1).

Table 1: Demographic determinants of AYUSH use.

\begin{tabular}{|c|c|c|}
\hline \multirow[t]{2}{*}{ Demographic } & \multicolumn{2}{|c|}{ Students $(\mathrm{n}=\mathbf{3 8 0})$} \\
\hline & $\begin{array}{l}\text { AYUSH users } \\
(\mathrm{n}=96)(\%)\end{array}$ & $\begin{array}{l}\text { Non AYUSH users } \\
(\mathrm{n}=284)(\%)\end{array}$ \\
\hline \multicolumn{3}{|c|}{ Year of medical school } \\
\hline $1^{\text {st }}$ year & $23(24)$ & $92(31)$ \\
\hline $2^{\text {nd }}$ year & $20(21)$ & $88(29)$ \\
\hline $3^{\text {rd }}$ year & $25(26)$ & $64(21)$ \\
\hline $4^{\text {th }}$ year & $28(29)^{*}$ & 57 (19) \\
\hline \multicolumn{3}{|l|}{ Sex } \\
\hline Male & $65(68)$ & $175(58)$ \\
\hline Female & $31(32)$ & $126(42)$ \\
\hline
\end{tabular}

$* \mathrm{p}<0.05$ was obtained on $\mathrm{Z}$ test 
The most common reason which prompted the patients to use AYUSH was due to recommendation from family and friends $(40.2 \%)$ followed by religious/spiritual beliefs $(20.2 \%)$. Very few students believed that AYUSH had fewer incidences of side effects (10.1\%) (Table 2).

Table 2: Reason for using AYUSH.

\begin{tabular}{|ll|}
\hline Reason Percentage of students $(\mathbf{n = 9}$ 6) \\
\hline Recommendation from friends and family & 40.5 \\
\hline Spiritual/ religious belief & 20.2 \\
\hline Less incidence of side effects & 10.1 \\
\hline Not satisfied with conventional medicine & 15.3 \\
\hline Success report from advertisement & 8.5 \\
\hline AYUSH is curative & 5.4 \\
\hline
\end{tabular}

Success report from advertisement AYUSH is curative

Family and friends (34.2\%) emerged as the major source of information about AYUSH followed by internet $(26.4 \%)$ and AYUSH student/practitioner (21.3\%).

\section{Perception about AYUSH}

The student's opinion on effectiveness of different AYUSH modalities was $68 \%$ for yoga followed by $45 \%$ of the students felt that ayurveda was effective while $30 \%$ of the students opined that siddha was harmful, $28.3 \%$ of the students felt that unani was harmful (Table 3). $71 \%$ of the students endorsed that AYUSH has certain elements from which conventional medicine could benefit while $25 \%$ of the students opined that AYUSH results are usually due to placebo effect. $35 \%$ of the participants agreed with the statement that AYUSH treatment could lead to serious adverse effects. Only $10 \%$ of the subjects felt that AYUSH is better than allopathic medicine. $73 \%$ of the participants were of the opinion that a patient's treatment should take into consideration all aspects of his or her physical, mental and spiritual health. $55 \%$ of the students said that they would suggest AYUSH to friends and family (Table 4).

Table 3: Self-perceived effectiveness of AYUSH among medical students $(n=380)$.

\begin{tabular}{|lcll|}
\hline $\begin{array}{l}\text { AYUSH } \\
\text { modality }\end{array}$ & $\begin{array}{l}\text { Effective } \\
(\boldsymbol{\%})\end{array}$ & $\begin{array}{l}\text { Harmful } \\
(\boldsymbol{\%})\end{array}$ & $\begin{array}{l}\text { No opinion } \\
(\boldsymbol{\%})\end{array}$ \\
\hline Ayurveda & 45.6 & 20.3 & 14.2 \\
\hline Yoga & 68.3 & 10.5 & 21.2 \\
\hline Naturopathy & 28.3 & 18.6 & 53.1 \\
\hline Unani & 32.6 & 28.3 & 39.1 \\
\hline Siddha & 20.9 & 30.5 & 48.6 \\
\hline Homeopathy & 35.4 & 25.4 & 39.2 \\
\hline
\end{tabular}

\section{Attitudes towards integrated medicine}

$60 \%$ of the students felt that integrated medicine is a better than using a single system of therapy. $45 \%$ of the students opined that AYUSH medicine should undergo rigorous scientific testing and then integrated in modern medicine. $80 \%$ of students opined that knowledge about commonly used AYUSH therapies is important to them in future clinical practice.

Table 4: Medical student's perception about AYUSH and integrated medicine.

\begin{tabular}{|c|c|c|c|}
\hline Statement & Agree $(\%)$ & Disagree $(\%)$ & No opinion (\%) \\
\hline $\begin{array}{l}\text { AYUSH includes ideas and methods from which conventional medicine } \\
\text { can benefit. }\end{array}$ & 71 & 17 & 12 \\
\hline Effects of AYUSH are usually the result of a placebo effect & 25 & 32 & 43 \\
\hline $\begin{array}{l}\text { When AYUSH modalities are found to be efficacious in treatment of a } \\
\text { disease, doctors should recommend them, even though these systems may } \\
\text { rely on unknown mechanisms }\end{array}$ & 41 & 26 & 33 \\
\hline AYUSH is a threat to public health & 20 & 37 & 43 \\
\hline $\begin{array}{l}\text { Health care professionals should be able to advise their patients about } \\
\text { commonly used AYUSH therapies }\end{array}$ & 70 & 18 & 12 \\
\hline $\begin{array}{l}\text { Integrating AYUSH with allopathy without any scientific basis could lead } \\
\text { to serious adverse effects }\end{array}$ & 38 & 24 & 38 \\
\hline AYUSH is more effective than allopathic medicine & 10 & 65 & 25 \\
\hline $\begin{array}{l}\text { A patient's treatment should take into consideration all aspects of his or } \\
\text { her physical, mental and spiritual health }\end{array}$ & 73 & 15 & 12 \\
\hline $\begin{array}{l}\text { Clinical care should integrate the best of conventional and Evidence based } \\
\text { AYUSH therapies }\end{array}$ & 60 & 16 & 24 \\
\hline
\end{tabular}

$266(70 \%)$ students were interested in learning basics of AYUSH. Among them $58 \%$ of the students endorsed that
AYUSH should be introduced as an elective course rather than a mandatory part of medical curriculum (Table 5). Regarding methods of AYUSH education, $35 \%$ of the 
students favoured didactic lectures in $3^{\text {rd }}$ year of MBBS, followed by short stint in AYUSH clinics as part of internship (30\%). $20 \%$ of the students opted for clinical posting in final year in AYUSH hospitals (Figure 3).

Table 5: Opinion on learning integrated medicine.

\begin{tabular}{|c|c|c|c|c|}
\hline \multicolumn{4}{|c|}{ Frequency } & Percentage \\
\hline \multirow{5}{*}{ 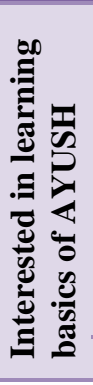 } & \multirow{4}{*}{ Yes } & $\begin{array}{l}\text { As mandatory part of } \\
\text { medical curriculum }\end{array}$ & 96 & 25.2 \\
\hline & & $\begin{array}{l}\text { As elective/optional } \\
\text { subject }\end{array}$ & 151 & 39.7 \\
\hline & & $\begin{array}{l}\text { Learn from } \\
\text { independently } \\
\text { conducted workshops }\end{array}$ & 19 & 5 \\
\hline & & Total & 266 & 70 \\
\hline & \multicolumn{2}{|l|}{ No } & 114 & 30 \\
\hline \multicolumn{3}{|l|}{ Total } & 380 & 100 \\
\hline
\end{tabular}

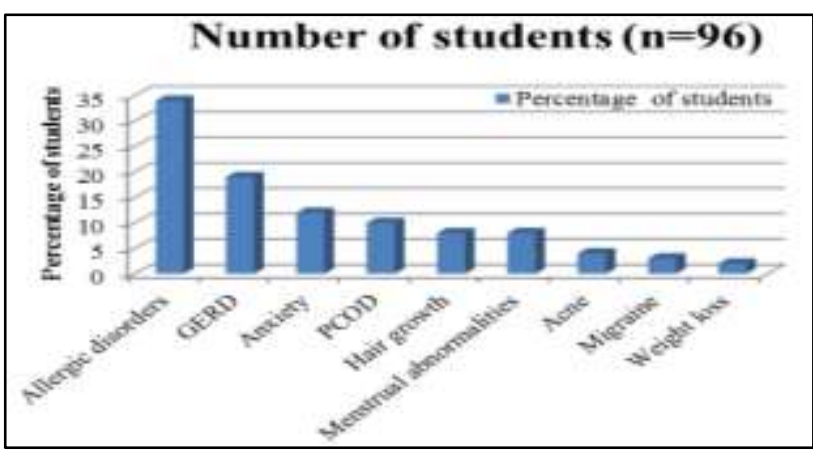

Figure 1: Indication/symptom for AYUSH use.

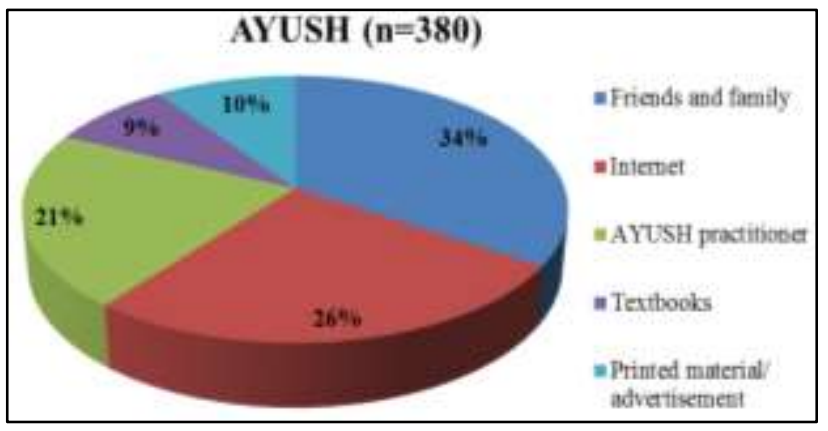

Figure 2: Source of information about AYUSH.

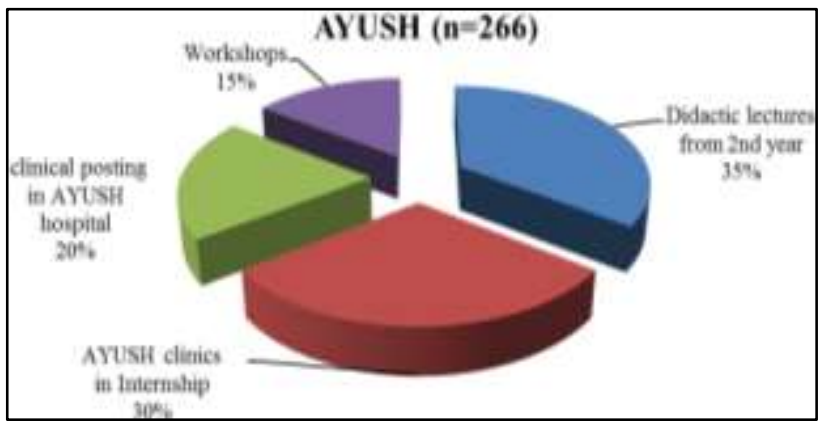

Figure 3: Students suggested method of AYUSH integration.

\section{DISCUSSION}

This descriptive study explored the perception and usage pattern of AYUSH among medical students and their opinion on integrative medicine education and practices. The response rate obtained was satisfactory and in sync with a study conducted in Pakistan. ${ }^{14}$ only $25 \%$ of the students personally used AYUSH which is less than that reported by a study conducted in Nepal (42.5\%). This could be because of socio-cultural differences and influence of religious and spiritual beliefs among the two populations.

While a majority of students opined that Yoga was highly effective, less than half of students thought that other AYUSH modalities were effective. This finding could be because of better understanding of yoga as Indian textbooks of physiology and internal medicine have chapters describing its principles and health benefits. A study done in Saudi Arabia comparing pre and post exposure attitude towards CAM reported a significant improvement in positive attitude post exposure. ${ }^{15,16}$ Based on this finding we can contemplate that AYUSH education might alter students perception to AYUSH and help in providing holistic care to patients.

Even though $266(70 \%)$ of the students were willing to incorporate AYUSH in future practice, only 93(25.2\%) among them were in favour of integrating AYUSH as a mandatory part of medical curriculum. Students who sought AYUSH for personal health and whose family members used AYUSH, had an overall favourable perception of AYUSH and significantly more likely to incorporate it in their future clinical practice. The reasons given against integration of AYUSH in existing medical curriculum were making AYUSH mandatory would lengthen the duration of medical education and increase the study burden. 151 (40\%) of students thought that introducing AYUSH as an elective course is a better proposition.

Overall the students had a positive attitude towards AYUSH and importantly $60 \%$ of them voted in favour of integrated medicine which could aid in successful execution of the ambitious plan of Indian government of providing health care for all by incorporating AYUSH with mainstream medicine.

\section{CONCLUSION}

Medical student's perception towards AYUSH and integrative medicine is positive. Students were in favour of learning AYUSH as an elective subject in medical curriculum.

\section{ACKNOWLEDGEMENTS}


The authors are grateful to Dr. Preeti Dharapur, Dr. Tharangini and Dr.Shruti Somani for their valuable assistance in data collection.

Funding: No funding sources

Conflict of interest: None declared

Ethical approval: The study was approved by the Institutional Ethics Committee

\section{REFERENCES}

1. GOI. Census of India. Government of India. Available at http://www.census2011.co.in/

2. Satpathy S. Public health infrastructure in rural India: challenges and opportunities. Indian J Public Health. 2005;49:57-62.

3. Press information Bureau, government of India. Available http://pib.nic.in/newsite/mbErel.aspx?relid=123729. Accessed 25 March 2016.

4. Report ministry of ayush to integrate allopathic and traditional forms of medicine. Available at http://www.dnaindia.com/india/report-ministry-ofayush-to-integrate-allopathic-and-traditional-formsof-medicine-2154290. Accessed 25 March 2016.

5. Roy V, Gupta M, Ghosh RK. Perception, attitude and usage of complementary and alternative medicine among doctors and patients in a tertiary care hospital in India. Indian Journal of Pharmacology. 2015;47(2):137-42.

6. Gawde SR, Shetty YC, Pawar DB. Knowledge, attitude, and practices toward ayurvedic medicine use among allopathic resident doctors: a cross-sectional study at a tertiary care hospital in India. Perspect Clin Res. 2013;4:175-80.

7. Kunnoor NS, Rathore R, Xavier D. Physicians perception on complementary and alternative medicine (cam): a cross sectional survey at tertiary care hospital in India. Med chem. 2015;5:197-202.
8. Kligler B, Maizes V, Schachter S, Park C, Gaudet T, Benn R, et al. Education working group. Core competencies in integrative medicine for medical school curricula: a proposal. Acad Med. 2004;79(6):521-31.

9. Bodeker G. Lessons on integration from the developing world's experience. BMJ. 2001;322:164-7.

10. Roy V. Time to sensitize medical graduates to the Indian systems of medicine and homeopathy. Indian Journal of Pharmacology. 2015;47(1):1-3.

11. Press release of Amrita university's launch of course on Integrative medicine. Available at https://www.amrita.edu/press-media/amritauniversity-launches-india\%E2\%80\%99s-first-centerintegrated-medicine-and-research. Accessed 26 March 2016.

12. Lie D, Boker J. Development and validation of the CAM health belief questionnaire (CHBQ) and CAM use and attitudes amongst medical students. BMC Medical Education. 2004;4:2.

13. Schneider CD, Meek PM, Bell IR. Development and validation of IMAQ: integrative medicine attitude questionnaire. BMC Medical Education. 2003;3:5.

14. Kashif M, Hussain M, Hussain RK, Saba M, Sana M, Khimani F. Complementary and alternative medicine: perceptions of medical students from Pakistan. Med Educ. 2007;12:11.

15. Dwivedi S, Narang S. Exercise and yoga in health and disease. In: API text book of Medicine, $9^{\text {th }}$ Ed. Jaypee Brothers Publishers; 2012:2061-63.

16. Al Mansour MA, Al-Bedah AM, AlRukban MO, Elsubai IS, Mohamed EY, El Olemy AT, et al. Medical students' knowledge, attitude, and practice of complementary and alternative medicine: a preand post-exposure survey in Majmaah University, Saudi Arabia. Advances in Medical Education and Practice. 2015;6:407-20.

Cite this article as: Somani $\mathrm{R}$, Vardhamane $\mathrm{S}$, Bidarimath B, Sajid M. Perception regarding AYUSH and integrative medicine among medical undergraduate students: a cross-sectional study. Int J Basic Clin Pharmacol 2016;5:1048-52. 